\title{
La propiedad intelectual y la mercantilización forzada del conocimiento
}

\section{Intellectual property and the forced commodification of knowledge}

\author{
Pablo Míguez \\ Instituto de Industria. Universidad Nacional General Sarmiento \\ (IDEI-UNGS) \\ Instituto de Altos Estudios Sociales. Universidad Nacional de San Martín \\ (IDAES-UNSAM-CONICET) \\ pmiguez@ungs.edu.ar \\ Código Orcid: https://orcid.org/0000-0002-4359-7113
}

\begin{abstract}
Resumen
Este trabajo propone analizar la creciente mercantilización del conocimiento a través del refuerzo de los derechos de propiedad intelectual a escala global como una expresión de un cambio en la lógica de la producción y de la valorización del capital, que supone el pasaje del capitalismo industrial a un capitalismo cognitivo. Retomando los debates recientes sobre los bienes comunes y las tesis del capitalismo cognitivo, procuraremos mostrar la necesidad de correspondencia de las regulaciones internacionales y de los sistemas jurídicos nacionales, con las necesidades de la valorización del conocimiento. Estudiaremos el origen y la evolución histórica de los derechos de propiedad intelectual y, con apoyo en evidencias empíricas provenientes de estudios específicos y fuentes diversas, señalaremos algunas circunstancias concretas que favorecieron los cambios en las regulaciones e instituciones.
\end{abstract}

\section{Palabras clave}

Propiedad intelectual, conocimiento, bienes comunes, capitalismo cognitivo.

\section{Abstract}

This paper analyzes the growing commodification of knowledge through the reinforcement of intellectual property rights, on a global scale. This process is an expression of a change in the logic of capital's production and valorisation, in the switch from industrial to cognitive capitalism. We recover the recent debates on commons and the theories of cognitive capitalism to show the need for stablishing a correspondence between international regulations and national legal systems, in order to valorize knowledge. We will study the origin and historical evolution of intellectual property rights and, based on empirical evidence obtained from specific studies and diverse sources, we will point out some concrete circumstances that favored changes in regulations and institutions.

\section{Keywords}

Intellectual porperty, knowledge, commons, cognitive capitalism.

Forma sugerida de citar: Míguez, Pablo (2018). La propiedad intelectual y la mercantilización forzada del conocimiento. Universitas, 29, pp. 43-65. 


\section{Introducción}

La "propiedad intelectual" fue impulsada a nivel internacional desde 1967 por el Acuerdo General de Aranceles y Comercio (GATT) en su intento por generar acuerdos a nivel mundial sobre la protección de las producciones de las empresas multinacionales, predominantemente norteamericanas. Las leyes nacionales sobre patentes existen desde el siglo XIX y fueron cuestionadas desde su nacimiento - aún en los países donde se desarrollaban los principales inventos de la era industrial - a causa de los límites que estas imponían a las posibilidades de "innovación tecnológica". No obstante, aunque todos los países desarrollados fueron protegiendo la propiedad intelectual, la legislación de patentes, marcas y derechos de autor varía según los países.

Este trabajo propone analizar la creciente mercantilización del conocimiento a través del refuerzo de los derechos de propiedad intelectual a escala global, como una expresión de un cambio en la lógica de la producción y de la valorización del capital que supone el pasaje del capitalismo industrial a un capitalismo cognitivo. Retomando los debates recientes sobre los bienes comunes y las tesis del capitalismo cognitivo, procuraremos mostrar la necesidad de correspondencia de las regulaciones internacionales y del sistema jurídico nacional, con las necesidades de la valorización del conocimiento. Estudiaremos el origen y la evolución histórica de los derechos de propiedad intelectual y, con apoyo en evidencias empíricas provenientes de estudios específicos y fuentes diversas, señalaremos algunas circunstancias concretas que favorecieron los cambios en las regulaciones e instituciones.

El concepto "propiedad intelectual" engloba una serie de marcos regulatorios sustantivamente diferentes entre sí y que requieren un estudio por separado. La Organización Mundial de la Propiedad Intelectual (OMPI) en su Declaración Mundial de la Propiedad Intelectual del año 2000, la define como:

Cualquier propiedad que, de común acuerdo, se considere de naturaleza intelectual y merecedora de protección, incluidas las invenciones científicas y tecnológicas, las producciones literarias o artísticas, las marcas y los identificadores, los dibujos y modelos industriales y las indicaciones geográficas (OMPI, 2000).

Como señala Igor Sádaba, son las leyes las que determinan si un objeto específico pertenece al dominio público o al dominio privado: 
Gran parte de los debates sobre la Propiedad Intelectual puede ser reducida a la dicotomía siguiente: arbitran sobre la cuestión de dónde se sitúa un objeto (un gen causante de la obesidad, el software para predecir terremotos, una línea celular obtenida de un bazo humano, un medicamento que cura el paludismo, los compases de una melodía de Mozart, etc.) en el espacio público o en el terreno privado, del lado de la individualidad o del lado del al colectividad (Sádaba, 2008, p. 136).

Bajo este esquema, el dominio público se está volviendo cada vez más reducido y el avance del dominio privado sucede en todos los aspectos de la actividad económica, colonizando la dimensiones sociales, culturales y de la vida en general.

En el primer apartado realizaremos un pequeño recorrido por el origen y la evolución de la protección de la propiedad intelectual hasta inicios del siglo XX, cuando quedan configurados dos modelos de protección: el anglosajón y el europeo. En el segundo apartado analizaremos el cambio que supone el pasaje de la garantía de derechos para el autor/inventor hacia la empresa/corporación a comienzos del siglo XX. En el tercer apartado nos ocuparemos del cambio surgido a finales de los años setenta, cuando se desdibujan las fronteras entre lo que es un invento y lo que es un descubrimiento. En el cuarto apartado nos ocupamos del efecto de esta normativa como un nuevo orden global con consecuencias específicas en América Latina. Finalmente, analizaremos siguiendo a Karl Polanyi el hecho de que la propiedad intelectual supone la "mercatilización del conocimiento" por medio de "mercancía ficticias"; mientras que en las conclusiones nos ocuparemos de las consecuencias de estas regulaciones, los beneficiarios y los perjudicados de la privatización forzada de lo común.

\section{Breve recorrido por la evolución de los derechos de propiedad intelectual}

Existe un acuerdo tácito sobre el origen de la propiedad intelectual con la aparición de la imprenta en el siglo XV, donde los autores y los impresores se unían para protegerse de las falsificaciones, al mismo tiempo que el Estado aceptaba conceder derechos de monopolio por su utilidad para fiscalizar los contenidos de lo que se imprimía. Fue la Revolución Inglesa de 1688 la que permitió la impresión libre, sin previa autorización, de la mano 
de los pensadores liberales. Sin embargo, la proliferación indiscriminada de copias hizo que en 1709 se dictara el Estatuto de la Reina Ana, que protegía más al editor que al autor; este estatuto protegía solo las palabras escritas por un período relativamente extenso, pero limitado a 28 años, dando inició así a las leyes del copyright.

En los derechos de autor de una obra se reconocían derechos patrimoniales de posesión y propiedad, pero no derechos morales de reconocimiento de su autoría, es decir, se trataba más de privilegios para la explotación de libros que una protección al autor. Dicha protección apareció luego como resultado de la Ilustración y la Revolución Francesa. La Enciclopedia dejó claro que el "derecho de copia" se desprendía del derecho de propiedad del escritor sobre sus obras. Los escritores se agrupaban en sociedades para defender sus intereses corporativos y obtenían derechos morales sobre sus obras, que no podían ser representadas en el teatro o modificadas sin su permiso. El autor era valorado como un productor o creador que trabajaba intelectualmente.

La patente, por su parte, también se originó en la Inglaterra mercantilista en el siglo XV con la concesión de privilegios monopólicos a comerciantes y fabricantes de manufacturas, pero - a diferencia de los derechos de autor - estas no podían venderse o cederse y requerían una descripción muy detallada de la invención para poder ser registradas. Una vez expirado el plazo del monopolio, la patente pasa al dominio público, por eso se requería que el inventor expusiera de manera detallada su secreto. La primera presentación equivalía al descubrimiento del "invento", permitiendo incluso la importación de técnicas desde el extranjero. En la Francia revolucionaria también se pide que se reconozca al propietario del invento como su inventor, en sintonía con las leyes británicas. Estados Unidos es el primer Estado moderno que sanciona leyes de patentes en 1790, para beneficio de los inventores y de la sociedad; luego, en 1836, crea la Patent Office y en 1897 la American Patent Law Association (Sádaba, 2008, p. 47).

Quedan configuradas entonces dos modalidades típicas de protección de la propiedad intelectual: el modelo europeo continental y el modelo anglosajón:

El modelo inglés es aún muy deudor de la imprenta, de la posibilidad de producir copias exactas y difundirlas. El modelo francés, en cambio, incorpora la idea de que la sociedad está compuesta por individuos con sus propios derechos, más fuertes que los de la colectividad (Sádaba, 2008, p. 34). 
El primero tiene su origen en la Francia previa a la Revolución Francesa y consolida un derecho de autor. El segundo se origina en Gran Bretaña en el siglo XVIII y es reformulado por Estados Unidos a fines del siglo XVIII. Al incorporarse de manera tardía al mundo industrial, Estados Unidos se posicionó durante el primer siglo de su historia en contra los derechos de propiedad intelectual de Gran Bretaña y otros países industriales, ya que no se reconocían derechos de copyright extranjeros, incluso aunque esto significara que las obras estadounidenses quedaran desprotegidas en el extranjero. La protección se otorgaba para garantizar la explotación de las ideas y asegurar la continuidad de los procesos creativos no sobre la base de un derecho moral del autor en tanto "propietario" de su obra (Sádaba, 2008, p. 140).

Tras la revolución de 1775 se procura sancionar normas que compensen la creación artística a cambio del fomento del progreso colectivo de la sociedad. De esta forma la Federal Copyright Act, de 1790, accede a conceder un monopolio de manera limitada a cambio del fomento a la innovación. Como veremos luego, las diferencias entre estos dos modelos se van a ir reduciendo con la aceptación irrestricta del copyright por parte de ambos (y de manera drástica desde finales del siglo XX).

Durante el siglo XIX se fue consolidando la protección de la propiedad intelectual en numerosos países $\mathrm{y}$, como veremos seguidamente, en el derecho internacional. Este proceso de concesión de derechos intelectuales se acelera a comienzos del siglo XX con la llegada del cine y con la posibilidad de la reproducción masiva de obras de arte, lo que genera la necesidad de una compensación económica para los autores y propietarios (de los financiadores antes que directores o realizadores), por lo cual se da la sanción de una nueva ley estadounidense, la Copyright Act, en 1909. El posterior auge de la radio y la televisión volverá más compleja todavía la asignación de derechos de autor. Como bien explica Sádaba:

Si en su momento la imprenta fue clave, no menos importante va a ser la aparición del fonógrafo, el cinematógrafo, la radio, el vídeo, Internet y todos los medios a través de los cuales tradicionalmente se han comunicado o se han transmitido contenidos en información (2008, pp. 36-37).

En el mismo sentido, Scout Forsyth señala que:

El cine es la avanzada estratégica - para decirlo en términos de la nueva jerga del negocio del espectáculo, la nave insignia - de un circuito de mer- 
cancías de consumo que incluye videos, televisión, Internet, historietas , novelas, juegos, juguetes, ropa comida rápida, parques y paseos temáticos. En este momento, las industrias del entretenimiento lideran las exportaciones de Estados Unidos (Forsyth, 2005, p. 145).

\section{Del inventor a las corporaciones}

A fines del siglo XIX existían diferentes formas de proteger la propiedad intelectual, cuya relevancia creciente llevó a la implementación a nivel internacional de las legislaciones, desde la Convención de Berna de 1886. Allí se reconoció internacionalmente el derecho de autor al creador y a sus derechohabientes hasta 70 años después de su muerte. No obstante, el derecho internacional sobre la propiedad intelectual va a tender a acercarse cada vez más al esquema del copyright (Sádaba, 2008, pp. 55-59).

Acorde con las transformaciones de la producción de la "gran empresa" del capitalismo industrial en ascenso, la innovación se desplazará desde el inventor a las corporaciones empresariales, a partir de las primeras décadas del siglo XX. En el capitalismo industrial, el mecanismo de producción de conocimientos se concentraba en los departamentos de investigación - tanto teórica como aplicada - de los organismos públicos y de las oficinas de Métodos y de I+D de la "gran empresa". El modelo de propiedad intelectual era coherente con un esquema donde la apropiación privada del saber se fundaba en recursos materiales y en el ámbito espacial del Estado nacional, donde la invención debía:

- Representar una novedad.

- Poder ser aplicada a nivel de la industria.

- Poder conciliar la remuneración del acto inventivo privado con la difusión pública del conocimiento.

Joseph Schumpeter $(2002 / 1939 ; 1944)$ fue uno de los primeros en celebrar este pasaje de la invención a la innovación, adjudicándole al empresario - el entrepreneur - que toma riesgos un rol protagónico. La invención alude a la mera generación de nuevos conocimientos o adelantos científicos y/o tecnológicos, mientras que la innovación supone la introducción exitosa de dichos conocimientos en la producción por parte de los empresarios, ya sea que se trate de un nuevo producto, un nuevo método de producción, una 
nueva fuente de materias primas o un cambio en la organización industrial. Las innovaciones reflejan una visión idealizada del empresario innovador - se asocia con nuevos "liderazgos" - por parte de Schumpeter y constituyen la causa principal de los ciclos largos y desequilibrios que caracterizan al sistema capitalista a partir de sucesivas "revoluciones tecnológicas" (grandes saltos tecnológicos derivados de innovaciones como la máquina de vapor, el ferrocarril, la electricidad o el transporte motorizado).

El rasgo innovador luego será adjudicado a las "firmas" por los economistas neoschumpeterianos y evolucionistas (Nelson y Winter, 1982; Dosi, Freeman, Nelson, Silverberg y Soete, 1988; Lundvall, 1992), dado que las innovaciones son costosas y arriesgadas y requieren, por tanto, un alto grado de concentración, así como recursos financieros suficientes para ser llevadas a cabo. Ellas se producen en el marco de determinados "paradigmas tecnológicos", los que dirigen el cambio técnico en la medida que definen los problemas relevantes, los patrones de investigación y la tecnología a utilizar hasta que se agota dicha fase con la difusión de los conocimientos, se desacelera el cambio técnico y se reducen las oportunidades de inversión (López, 1996). Para ellos, las patentes aseguran la innovación, es decir, generan los incentivos necesarios para innovar, ya que la innovación depende de limitar la difusión de la tecnología hasta que la renta tecnológica permita recuperar ese esfuerzo innovador.

La propia historia económica norteamericana parece confirmar este punto, cuando el capitalismo corporativo acelera la separación entre propietarios y gerentes desde las primeras décadas del siglo XX. Como señala David Noble (1979) en American by design, el propio poderío económico norteamericano durante el siglo XX fue condicionado, en buena medida, por leyes de propiedad intelectual adaptadas al reconocimiento de la propiedad de los inventos científicos y tecnológicos a las firmas, a los laboratorios de las grandes compañías. Las patentes serán propiedad de las grandes corporaciones en lugar del inventor o científico empleado que las desarrolló, quienes a cambio solo recibían un ingreso regular en forma de salario.

En suma, a lo largo de la evolución de la protección a la propiedad intelectual podemos diferenciar dos modelos fundamentales: el modelo anglosajón de Inglaterra y Estados Unidos basado en el Common Law y el modelo europeo basado en el derecho continental. En el modelo jurídico norteamericano las leyes de patentes establecen los principios generales, pero es la Oficina de Patentes la encargada de dar su versión sobre la apli- 
cación de la norma, en última instancia es esta la que tiene la capacidad de crear jurisprudencia, pues la Corte Suprema interviene solo cuando ella misma lo decide, lo que sucede en algunos pocos casos. Los tribunales clásicos, formados en la doctrina antitrust, eran históricamente reacios a otorgar patentes, pero esta situación iba a cambiar con el surgimiento, a comienzos de los años ochenta, de numerosas leyes y varios fallos de la Corte Suprema de Justicia estadounidense que transformaron radicalmente la situación (como la decisión de patentar los genes, contra la opinión de la Oficina de Patentes), como veremos en el siguiente apartado (Coriat, 2008, p. 57).

Durante los primeros 100 años de aplicación de las leyes de patentes Estados Unidos desconocía los derechos de copyright otorgados en el extranjero, pero desde los años setenta, a partir de su influencia en los organismos internacionales, a instancias de este país se procura homogeneizar las legislaciones con marcos jurídicos de implementación única en todo el mundo para favorecer el despliegue de sus industrias, sobre todo en el plano cultural y del entretenimiento (Lessig, 2005, p. 84). Estados Unidos detenta un elevado número de otorgamiento de patentes sobre el total de patentes solicitadas y en su territorio se asiste a las mayores batallas judiciales en torno a violaciones a las leyes de patentamiento. Esto hace que muchas empresas se dediquen a la acumulación de patentes no para su utilización, sino para demandar a pequeños emprendedores o para negociar entre las grandes compañías acuerdos de uso de patentes en condiciones más favorables.

\section{Del invento al descubrimiento}

En la década de 1920 comienzan a darse los primeros pasos en el patentamiento de "descubrimientos" - ya no sólo de inventos - , cuando los conocimientos básicos - los originados por la ciencia básica sin haber sido aplicados (o desconociendo su potencial aplicabilidad) - comienzan a ser objeto de patentes. No importaba que ya existieran en la naturaleza y que no fueran, por lo tanto, una creación humana. Por ejemplo, en 1922 Pasteur había patentado un proceso sobre una bacteria dando comienzo a las "patentes sobre organismos vivos" y en 1930 Estados Unidos sanciona una ley de patentes sobre plantas. También hacen lo suyo los floricultores holandeses que reciben patentes con la promesa de no tocar la reproducción sexual de las semillas. Sin embargo, no será hasta la década de 1960 que la cuestión retoma- 
rá un verdadero impulso. Más emblemático aún es el caso de la industria del cine de Hollywood. La creación en California del complejo cinematográfico responde a la huída de empresarios de la costa este, donde debían respetar las patentes de Thomas Edison. La guerra de patentes duró hasta que nueve compañías se fusionaron en la Motion Picture Patents Company (MPPC) (Sádaba, 2008, p. 130).

Un momento importante se da en 1970, cuando Estados Unidos sanciona una nueva ley de patentes, en el mismo año que impulsa la OMPI. En esta década se producen cambios fundamentales desde que en 1975, por decisión de la Corte Suprema, los microorganismos pasan a ser patentables (caso "Bayer Yeats"). Sin embargo, estos cambios jurisprudenciales en el territorio estadounidense, si bien son importantes, no pueden ser vistos de manera aislada. En el capitalismo contemporáneo, el conocimiento pasa a ser central por razones sociales e históricas antes que tecnológicas, y preceden a la constitución del capitalismo cognitivo. Estos cambios se deben fundamentalmente a la democratización de la enseñanza - con la consecuente elevación del nivel general de formación-, que facilitó la constitución de una "intelectualidad difusa" que está en la base de la emergencia de una economía fundada en el rol motor del conocimiento (Lebert y Vercellone, 2006).

También debemos tener en cuenta la coyuntura del capitalismo fordista con su crisis de rentabilidad en los años setenta y con su necesidad de relanzar las bases de la acumulación. Según Coriat (2008), el despegue de la propiedad intelectual como factor decisivo de la valorización capitalista contemporánea debemos rastrearlo en la búsqueda por parte de Estados Unidos del restablecimiento de su competitividad erosionada por numerosos países - especialmente Alemania y Japón - , que lo desafiaban apoyándose en desarrollos tecnológicos basados en investigación básica, de la cual Estados Unidos era el responsable en un 50\% a nivel global. Estos cambios van a suponer una brutal aceleración de los procesos de mercantilización del conocimiento a comienzos de los años ochenta. En 1980 va a sancionarse la BayhDole Act, a partir de la cual los productos de la investigación desarrollados con fondos del Gobierno norteamericano pueden ser patentados y dejar, por tanto, de formar parte del dominio público. Adicionalmente, los propietarios de patentes podrán otorgar licencias exclusivas con la condición de que se realice a empresas ubicadas en el territorio norteamericano (sección 204). Se trata de una norma fundamental, que significó un punto de quiebre en muchos sentidos, especialmente debido a la obligación de la Secretaría de 
Comercio de informar al Congreso el listado de los países que no respetan la propiedad intelectual en perjuicio de las empresas estadounidenses (sección 301). Se preveía, además, la extensión de los plazos de protección de las patentes en numerosos sectores, así como la creación de tribunales arbitrales para dirimir este tipo de conflictos.

En rigor, será en 1980, con la obtención a favor de General Electric de la primera patente sobre un microorganismo - que fagocita las manchas de petróleo-, cuando se dé el verdadero golpe inicial a las patentes sobre la vida (el caso "Chakrabarti"). En pocos años, los hospitales y universidades se lanzaron en una carrera de solicitudes de patentes por "invenciones" que contenían material biológico, llegándose al caso extremo de científicos que patentaban sus descubrimientos aún antes de publicarlos. Este sistema creado para Estados Unidos se extendió a Europa, donde fue aceptado en el Parlamento Europeo con resistencias en puntos como la propiedad sobre los genes y los algoritmos, sin embargo, no pasó lo mismo en la Comisión Europea (Coriat, 2008, p. 59).

En suma, hay dos momentos claves a partir de la segunda posguerra: la creación de la OMPI en 1970 y el cierre de la Ronda Uruguay del GATT de 1986-1994, que creó la Organización Mundial del Comercio (OMC). Tras cada uno de estos acontecimientos asistimos a una relanzamiento de las solicitudes de protección de la propiedad intelectual que condicionan actualmente la innovación tecnológica. La década de los noventa trajo una explosión de la propiedad intelectual, pues las empresas transnacionales (ETN), especialmente norteamericanas, se lanzaron a obtener patentes de todo tipo para beneficiarse de la denominada "globalización". En 1994, en el cierre de la Ronda Uruguay del GATT, los países consideraban un asunto comercial bajo la protección de la naciente OMC, donde los firmantes debían comprometerse, entre otras cosas, a la protección de la propiedad intelectual de todo tipo por la vía de los Acuerdos sobre Aspectos de Propiedad Intelectual Relacionados al Comercio (AADPIC). En fin, el boom de la biotecnología de los años ochenta, el auge de la manipulación genética y de la industria farmacéutica, le deben mucho a la evolución de las patentes, pues estas áreas ya no se van a ver obligadas a realizar sus propias investigaciones para desarrollar productos, sino que pueden obtener licencias de universidades, instituciones públicas o pequeñas empresas tecnológicas surgidas generalmente como un spin off de las primeras.

En Europa las objeciones a la adopción inmediata del sistema norteamericano son sostenidas con sólidos fundamentos jurídicos, ya que la secuen- 
cia de un gen o un algoritmo no tendrían, en principio, ninguna utilidad industrial. Bercovitz agudamente señala que:

En el Convenio Europeo de Patentes de 1973 se mantiene esta exigencia, al exigir que las invenciones patentables sean susceptibles de aplicación industrial, lo cual equivale en la doctrina tradicional a exigir que las invenciones patentables sean invenciones técnicas, entendida la técnica como técnica industrial (2003, p. 18).

Bercovitz también subraya que el convenio AADPIC establece que "susceptibles de aplicación industrial" es sinónimo de "útiles", mas no distingue la diferencia:

Útiles, en el sentido que satisfacen necesidades humanas, son todas las invenciones, sean o no industriales. Y esta distinción entre utilidad y susceptibilidad de aplicación industrial tiene importancia porque en la legislación norteamericana no se contiene expresamente la exigencia de que las invenciones patentables sean industriales, aunque sí se exigen que sean útiles. Por ello los planteamientos sobre patentabilidad aplicados en los Estados Unidos no pueden ser trasladados pura y simplemente al Derecho europeo (Bercovitz, 2003, p. 18).

En el caso europeo, los países son más minuciosos en la definición de aquello que puede caer en el ámbito de lo patentable. En materia de patentes, en Europa se habla de "propiedad industrial", esto significa que solo pueden concederse a invenciones industriales, aunque la tendencia es cada vez más a acercarse al modelo norteamericano. Allí se hace cada vez menos rigurosa la demostración de la aplicación industrial de los resultados de la investigación y más borrosa la línea que divide lo que es un invento y un descubrimiento.

\section{Una nueva institucionalidad global y su impacto en América Latina}

De acuerdo a Saskia Sassen (2010), la entrada en vigencia el Acuerdo de Marrakech que fundaba la OMC en 1995 supuso el nacimiento de un nuevo derecho económico internacional, ya que regulaba el $97 \%$ del tráfico comercial internacional y obligaba a los países menos desarrollados a adoptar el AADPIC, que asigna una función permanente a la OMPI en actividades de 
cooperación. La OMPI es la institución creada por los Estados para aplicar los convenios multinacionales sobre propiedad intelectual, así como los Tratados de Internet y los convenios europeos sobre derechos de autor. Como las normas internacionales de la OMC deben incorporarse al derecho nacional, esto supone "nuevas formas de autoridad privada" como los sistemas de arbitraje, puesto que hay que "dejar de lado la solución de conflictos entre ordenamientos jurídicos nacionales y reenfocarse en los conflictos entre regímenes sectoriales, como ocurre cuando existen diferencias entre la OMPI, la OMC, la UE y los derechos nacionales" (Sassen, 2010, pp. 304-305).

La protección de la propiedad intelectual se constituye en la punta de lanza del cambio de régimen jurídico internacional que supone la des-nacionalización de los Estados nacionales (Sassen, 2007), o mejor aún, "de varios componentes institucionales especializados" de ellos. Pero esto no supone una disminución de las jerarquías ni la desaparición de la soberanía de los Estados:

Ciertos Estados, como el de Gran Bretaña y Estados Unidos, producen en efecto la formulación de esta nueva legalidad y la imponen a otros estados gracias a las interdependencias que caracterizan la etapa actual de la globalización. Incluso así, los estados participantes necesitan desarrollar sus propios instrumentos específicos en función de los ordenamientos político económicos que rigen en su interior (Sassen, 2010, pp. 290-291).

Estados Unidos condujo o forzó a otros Estados a adoptar esas obligaciones con el capital global, luego de una amplia experiencia en la ampliación de las operaciones transfronterizas para las empresas estadounidenses. Ya no se trata centralmente de respaldar a las industrias estratégicas, sino de crear las condiciones de competitividad para una economía global (Sassen, 2010 , p. 300). Estos cambios de la producción y la valorización basadas en el conocimiento obligan a discutir las relaciones entre la lógica "global" del capital y la dimensión "territorial" de las formas políticas asumidas por ella (Negri y Hardt, 2002, 2011; Míguez, 2015, 2017).

El problema con este esquema es que su difusión por todo el mundo a partir del Consenso de Washington y las normas de la OMC desde la Ronda Uruguay 1986-1994, impone condiciones muy desventajosas para los países en desarrollo. Para ingresar a la OMC los países deben cumplir acuerdos como el TRIPS (Trade Related Aspects of Intellectual Property Rights) de 1995, que buscaba reforzar la protección de la propiedad intelectual a partir de procedimientos y legislaciones a escala internacional, obligando a las naciones fir- 
mantes a crear mecanismos administrativos y penales respecto a derechos de propiedad intelectual y facultando al Sistema de Solución de Controversias de la OMC para actuar si surgen diferencias comerciales en torno a ellos, los cuales se comenzaron a aplicar en el año 2000 (Sádaba, 2008, p. 70).

En América Latina, estas disposiciones se vieron impulsadas en un primer momento por el NAFTA, creado en 1992, para que México se adapte a las normativas de Estados Unidos y Canadá. El NAFTA había sido el modelo para las normas de la OMC de 1994 y luego por el Proyecto ALCA, un proyecto de zona de libre comercio desde Alaska a Ushuaia que se impulsó desde 1998 hasta su rechazo en 2005. Ante el fallido intento por imponer el ALCA, Estados Unidos ha promovido numerosos tratados bilaterales de libre comercio (TLC) con varios países de América Latina. Es el caso de los tratados comerciales con Costa Rica, donde las leyes de propiedad intelectual de la OMPI se incluyen dentro de un paquete más general que incluye normas para el comercio internacional. Estados Unidos también impulsa en América Latina iniciativas multilaterales como la Alianza del Pacífico, que incluye a México, Colombia, Perú y Chile, y desde 2009 - a nivel globalel Acuerdo Transpacífico (conocido como TPP por sus siglas en inglés), creado entre Chile, Nueva Zelanda, Singapur y Brunei en 2005 y firmado luego por Estados Unidos, Canadá, México, Perú, Vietnam y Malasia, que solo entrarán en un impasse desde 2016 con el Gobierno de Donald Trump. Todavía está por verse si se trata de un efectivo revés a las normas del libre comercio o solo de medidas específicas para proteger a sectores industriales retrasados de Estados Unidos, que no son los beneficiarios principales de las normativas globales. El TPP se proponía organizar las nuevas reglas del derecho económico global del siglo XXI, en línea con la Asociación Transatlántica para el Comercio y la Inversión (conocido como Tratado Transatlántico o TTIP), una propuesta de libre comercio entre Estados Unidos y la Unión Europea sobre la base de la regulación del comercio, los servicios, la inversión y la propiedad intelectual (Merino, 2018, p. 23).

Los acuerdos regionales como el Mercosur o la CELAC intentaron avanzar en un bloque económico y político regional desde la caída del proyecto ALCA en 2005 y realizaron sustantivos avances en esta dirección, como la consolidación de un sistema de solución de controversias de carácter permanente, el Fondo de Convergencia Estructural del Mercosur (FOCEM) para resolver las asimetrías entre los países miembros y el Parlamento del Mercosur (Parlasur) para la representación directa de lo ciudadanos del bloque. En 
relación al conocimiento, como parte del intento de promover la integración productiva sobresale el Programa Marco de Ciencia y Tecnología y el Programa de Apoyo a la Biotecnología en la Plataforma Biotech, que se proponen promover innovaciones tecnológicas (dado el auge del agronegocio en la región). Esta segunda iniciativa es impulsada y a la vez condicionada por la Unión Europea, que es la fuente de financiamiento de estas actividades y que por ello pretende ser la propietaria de los derechos de propiedad derivados de estas iniciativas (Perrota y Porcelli, 2016).

Una de las excepciones notables a estos avances en el ámbito latinoamericano fue la iniciativa del Código Orgánico de la Economía Social de los Conocimientos, la Creatividad y la Innovación (conocido popularmente como el Código Ingenios) en Ecuador, donde se juntó en un solo cuerpo jurídico las normas sobre ciencia, tecnología e innovación, con los saberes ancestrales y la propiedad intelectual (Pazos, 2016, p. 553). El Código deroga la Ley de Propiedad Intelectual y aprovecha las flexibilidades de las normas internacionales promoviendo un equilibrio entre los derechos de los titulares y los usuarios, en procura de objetivos de desarrollo (Ramírez, 2014, pp. 49-54). Sin embargo, el cambio de signo de los Gobiernos de la región desde 2015 y la renovada preferencia por el "regionalismo abierto" de los años previos, llevan a priorizar la celebración de acuerdos de libre comercio como el MERCOSUR-Unión Europea, que en los hechos implican un renovado fortalecimiento de la propiedad intelectual.

\section{Nuevas mercancías "ficticias"}

El conocimiento - como los bienes de la naturaleza - debe ser considerado un bien común, y la forma de gestionarlo así como la propiedad de los bienes comunes es de hecho anterior a la basada en la distinción público/ privado. La privatización de las tierras comunes entre los siglos XV y XVI fue determinante en el proceso de desposesión de los productores, característico de la acumulación originaria, y fue condición necesaria para el desarrollo del capitalismo. Como señala Polanyi, la Tierra - en tanto producto de la naturaleza - no es producto del trabajo humano y es, por lo tanto "una mercancía ficticia". Es falso suponer que la mano de obra, la Tierra y el dinero sean mercancías, pero a partir de o con la ayuda de, esta ficción se organizan los "mercados", y lo más importante: se vuelven el principio organizador de la sociedad. 
El punto crucial es este: la mano de obra, la tierra y el dinero son elementos esenciales de la industria: también deben organizarse en mercados; en efecto, estos mercados forman una parte absolutamente vital del sistema económico. Pero es obvio que la mano de obra, la tierra y el dinero no son mercancías; en el caso de estos elementos, es enfáticamente falso que todo lo que se compra y se vende debe haber sido producido para su venta (Polanyi, 1992, p. 81).

Haciendo de la Tierra una mercancía se instala el principio de la propiedad privada y el principio de lo público-privado como los principios organizadores del orden económico y social, dejando al margen lo "común".

En la primera mitad del siglo XX la teoría económica convencional teorizó sobre los bienes públicos. A diferencia de los bienes privados, que son rivales (el aumento de la cantidad consumida por un individuo implica necesariamente la reducción de la cantidad consumida por otro) y excluyentes ( se puede excluir a un individuo del consumo de un bien mediante el sistema de precios), los bienes públicos son aquellos bienes donde el costo marginal de producir una unidad adicional es nulo. Asimismo, son bienes no excluyentes, no se puede excluir a ningún agente del consumo de dicho bien (por ejemplo, del alumbrado público), lo que justifica su provisión desde el Estado, ya que puede obtener el "precio" a través de los impuestos, a condición de que se reflejen las condiciones de equilibrio del mercado (precio positivo e igual al costo marginal). Adicionalmente, aparece el problema del free-rider, la posibilidad de un individuo de ocultar sus preferencias y acoplarse al consumo del bien sin pagar. Como vemos, lo que se muestra es un problema teórico y práctico, que el mercado no sirve para revelar las preferencias de los individuos, no se puede estimar la demanda y el oferente no sabe cuánto debe ofrecer del producto, alterando el funcionamiento fluido y equilibrador del mercado, justificando la provisión de dichos bienes por el Estado (seguridad y administración de justicia son ejemplos clásicos de bienes públicos).

El proceso político debe, entonces, reemplazar la ausencia de demanda, permitir revelar las preferencias de los consumidores/ciudadanos y determinar la oferta de bienes públicos. Sin embargo, que exista una "falla de mercado" no implica necesariamente la producción desde el Estado de dicho bien, pero sí al menos su financiamiento o la regulación de la actividad estableciendo una tarifa en el caso de las concesiones de servicios públicos o la creación de incentivos a la eficiencia mediante la creación o exención de impuestos o el otorgamiento de subsidios. 
En el período de auge del Estado keynesiano-benefactor, el hecho de que el Estado se encargara de la provisión de numerosos bienes públicos requería elaborar una justificación que permitiera congeniar dicha provisión con la subsistencia de los principios de la economía neoclásica. En ese contexto surge la idea de la Tragedia de los comunes (Hardin, 1968), donde se concluye que la acción racional e individual de explotación de bienes de la naturaleza, en tanto busca la maximización del bienestar individual, termina sobreexplotando el recurso natural y eliminando los beneficios comunes, de lo cual se deriva una justificación para la propiedad privada de los mismos. Con dichos argumentos también se pretende "proteger" en la actualidad a los productos del conocimiento, lo que deriva en un efecto contraproducente, denominado por Michel Heller, la Tragedia de los anticomunes (1998), esto es, la creación de un sistema que sub-utiliza el conocimiento a causa del patentamiento exagerado de bienes. Ello impide la libre utilización de los conocimientos porque se quiere estimular el crecimiento promoviendo la innovación, pero al mismo tiempo se bloquea la difusión de las innovaciones, lo que es una contradicción del capitalismo cognitivo que debería ser resuelta si se quiere construir una verdadera economía fundada en los conocimientos.

En el caso de los bienes de la naturaleza, subrayar el carácter común de estos bienes se propone como objetivo la conservación de recursos escasos y no renovables. Desde la economía neoclásica convencional, Elinor Ostrom (1990) - la investigadora de la escuela de Indiana que recibió el Premio Nobel de Economía en 2009- ha planteado una salida alternativa a la privatización, que consiste en alcanzar acuerdos adecuados entre los participantes basados en reglas claras, supervisiones recíprocas y compromisos mutuos, articulados para la búsqueda del bien común. En el caso del conocimiento, de forma alternativa a los principios individualistas de la economía neoclásica, el economista italiano Vercellone (2017) propone plantear lo común como "modo de producción", que tiene como punto de partida la transformación de la colaboración en el trabajo. Se trata justamente de un bien común que no es escaso, sino abundante, acumulable, "no rival" y "no excluible". Como no es susceptible de sobreexplotación y no justifica, por lo tanto, la propiedad privada de los mismos:

No sólo el capital, sino el mismo producto del trabajo es cada vez más inmaterial y se incorpora en bienes de innovación, de conocimiento, en servicios 
informáticos que constituyen mercancías ficticias. ¿Por que mercancías ficticias? Son mercancías ficticias porque escapan a los criterios que definen las mercancías tradicionales en razón de su carácter no competitivo, acumulativo y difícilmente excluible (Vercellone, 2009, p. 90).

Para algunos autores, los derechos de propiedad intelectual constituyen "nuevos cercamientos" o enclosures, de la misma forma que durante la llamada Acumulación Originaria las leyes de cercamientos de la tierra imponían las condiciones iniciales para el despliegue de la acumulación capitalista convencional. Esta vez estos cercamientos tendrían como objetivo imponer las bases de un capitalismo sustentado sobre nuevos pilares, un "capitalismo cognitivo" donde la producción de bienes inmateriales impone su hegemonía a la producción típica del período industrial clásico o fordista. En el capitalismo cognitivo, la propiedad intelectual es reforzada porque es el único mecanismo que permite la apropiación privada del conocimiento crecientemente social y su control es estratégico para la valorización del capital. Destaca Moulier Boutang que esta nueva "gran transformación" que significa el capitalismo cognitivo - tomando los términos de Karl Polanyi- hace necesaria la creación de nuevas "mercancías ficticias" como la introducción de mecanismos de escasez "artificiales", "para limitar temporalmente su difusión y para reglamentar el acceso" (Rullani, 2002). En ese sentido, Boutang señalaba en 2001 que:

El capitalismo cognitivo se encuentra en su fase de acumulación primitiva, en el sentido de que el conjunto de los derechos de propiedad instaurados entre los siglos XVII y XVIII, y a partir de los cuales ha razonado la economía política clásica - y que a su vez a contribuido a perfeccionar y legitimarconstituye un límite infranqueable para la inscripción del potencial de desarrollo de las fuerzas productivas de la actividad humana en una trayectoria de crecimiento regular y en el marco de un compromiso institucional con las fuerzas de la vieja economía (Moulier Boutang, 2004, p. 111).

Para Boutang, los viejos derechos de propiedad son un límite para el desarrollo de las fuerzas productivas en la medida que no permiten aprovechar los efectos productivos positivos y gratuitos ("externalidades positivas" en la jerga económica convencional) de las múltiples interacciones de una economía basada en el conocimiento, una actividad gratuita, incesante y continua. Si se obliga a recurrir al intercambio mercantil para la producción de bienes conocimiento-intensivos se estaría privando a la sociedad de una de 
las fuentes esenciales de la productividad de los agentes económicos (Moulier Boutang, 2004, p. 116).

En el mismo sentido se expresa el geógrafo David Harvey, para quien los mecanismos de la acumulación primitiva se perfeccionaron para dar origen a nuevos mecanismos de acumulación por desposesión:

La insistencia en los derechos de propiedad intelectual en las negociaciones de la OMC (El llamado acuerdo TRIPS) indica cómo se pueden emplear ahora la patentes y licencias de material genético, plasma de semillas y muchos otros productos contra poblaciones enteras cuyas prácticas han desempeñado un papel decisivo en el desarrollo de estos materiales (Harvey, 2003, p. 118).

Los juristas de la Universidad de Stanford, especializados en el estudio de la propiedad intelectual como James Boyle y Lawrence Lessig, coinciden con estas consideraciones ante la privatización de bienes comunes que a priori estaban excluidos del derecho de propiedad (Vercelli, 2004). Afirma James Boyle (2003) que aquello que se conoce como enclosure forma parte de un movimiento de privatización de los bienes comunes o bienes que estaban fuera del sistema propiedad. Lo que se conoce como la tragedia de los bienes comunes se dio primero en Inglaterra y luego en otras regiones europeas, durante el siglo XVIII. Yochai Benkler (2003) y Lawrence Lessig (2005), al discutir el alcance de la propiedad intelectual, propusieron actualizar el debate sobre los "bienes comunes", como son los recursos naturales y el propio conocimiento. Si a los bienes privados y a los bienes públicos corresponden la propiedad privada o la propiedad pública, a los bienes comunes les debería regir la no propiedad (Lessig, 2005). La posibilidad del capital de poner a trabajar al común surge de una nueva organización de la producción que necesita de la valorización del trabajo, pero bajo modalidades novedosas y sofisticadas.

\section{Conclusiones}

A lo largo de este trabajo hemos indagado en el origen y la evolución de los derechos de propiedad intelectual desde los primeros derechos de autor hasta las patentes, desde la protección otorgada a inventores individuales hasta su atribución contemporánea a las grandes corporaciones. Señalamos también el cambio en la materia que es objeto de derechos de propiedad in- 
telectual, su ampliación incesante e ilimitada más allá de los inventos hacia los descubrimientos y su extensión final hasta el patentamiento de la vida misma. Todo ello supone dar lugar a nuevas mercancías ficticias acompañadas de marcos jurídicos regulatorios de carácter nacional y global que son la condición de posibilidad del sostenimiento de dicho avance.

Procuramos establecer las claves para comprender el sentido del avance de la protección de la propiedad intelectual en los más diversos campos, incluso más allá del estrictamente vinculado a la economía propiamente dicha y en todos los niveles políticos: ya sean estatales, regionales o globales. Para ello establecimos la necesidad de pensar el conocimiento como un bien común, indispensable en una nueva lógica de la acumulación basada en la generación y apropiación de conocimientos donde estos se convierten en una mercancía fundamental que supone - parafraseando el título del célebre libro de Piero Sraffa (1975) - la "producción de conocimientos por medio de conocimientos".

Los principales beneficiarios - interesados e impulsores - de la proliferación de los derechos de propiedad intelectual son las grandes industrias y las grandes firmas de los sectores tecnológicos destacados durante el último cuarto de siglo, por ejemplo, la industria farmacéutica, las tecnológicas y las que sobresalen en el plano cultural y de entretenimiento, pues todas ellas se construyeron y se sostienen gracias a estos derechos. La industria de los medios está plagada de historias sobre copias de contenidos, pero hoy son los principales impulsores de la propiedad intelectual, en parte debido a que los ingresos por royalties y derechos constituyen actualmente el principal rubro de exportación de la industria norteamericana. Esto no debe sorprender, ya que la historia del ascenso en la economía mundial señala que los países que impulsaron deliberadamente el desarrollo siempre necesitaron de políticas industriales, comerciales y tecnológicas activas que incluyeran copiar desarrollos tecnológicos, de forma que cuando finalmente alcanzaron el status de países "desarrollados" no permitirían el mismo comportamiento de los países en vías de desarrollo... según la célebre expresión de Ha-Joon Chang, ellos dieron una "patada a la escalera" (Chang, 2002).

Los principales perjudicados de las leyes de propiedad intelectual son todos aquellos que pretenden disponer libremente de los conocimientos socialmente generados. La sociedad como un todo no percibe beneficios de estos "nuevos cercamientos". Tampoco los perciben los pueblos originarios que durante siglos se han dedicado a mejorar las semillas y que ven sus esfuerzos capturados por empresas multinacionales que luego les imponen sus 
lógicas rentistas. También se perjudican las empresas pequeñas y medianas que, para realizar una investigación - frente a la proliferación de las patentes más inverosímiles y ante la necesidad de desarrollar una innovación propia - probablemente infringirán alguna patente ya existente. Esta situación las colocaría en desventaja respecto a las grandes empresas, muchas de las cuales se dedican sobre todo a acumular patentes no necesariamente para utilizarlas, sino para evitar que otros las usen o como moneda de cambio frente a otras empresas grandes con las cuales concretan acuerdos de uso de patentes, perjudicando a las empresas pequeñas y favoreciendo la centralización del capital.

Probablemente las consecuencias derivadas de estos avances de la protección de la propiedad intelectual sigan teniendo lugar habida cuenta de la centralidad que adoptan como mecanismos de generación y apropiación privada de conocimientos comunes. Este recorrido deberá completarse en el futuro con estudios de caso que diferencien sectores, países y niveles de desarrollo relativo, para evaluar el impacto concreto de estas iniciativas que seguirán teniendo un lugar central en la governance del capital global. Esta gestión política de la acumulación a escala global no estará exenta de conflictos, en la medida que en este capitalismo cognitivo una de las contradicciones más evidentes radica en el hecho de procurar la difusión del conocimiento y de la información, y a la vez bloquear el desarrollo de los conocimientos con las regulaciones crecientes sobre la propiedad intelectual. Vercellone subraya muy claramente esta dimensión contradictoria del intento de captar lo común. Se trata entonces de pasar de un capitalismo cognitivo a una verdadera economía basada en el conocimiento, para lo que requerimos formas de propiedad públicas, comunes o mixtas, adecuadas a tales fines.

\section{Bibliografía}

Benkler, Y. (mayo/junio, 2003). La economía política del procomún. Novatica/Upgrade, 163, 6-9. Madrid: ATI.

Bercovitz, A. (mayo/junio, 2003). Sobre la patentabilidad de la invenciones referentes a programas de ordenador. Novatica/Upgrade, 163, 17-21. Madrid: ATI.

Boyle, J. (2003). The Second Enclosure Movement and the Construction of the Public Domain. Law and Contemporany Problems, 66(12), 33-74. Recuperado de https://bit.ly/2AHB23X/ 
Chang, H. J. (2002). Kicking Away the Ladder.Development Strategies in Historical Prespective. Londres: Anthem Press.

Coriat, B. (2008). El régimen de la propiedad intelectual y la innovación. Realidad Económica, 233(37), 49-65. Buenos Aires: IADE.

Dosi, G., Freeman, C., Nelson, R., Silverberg, G. y Soete, L. (eds.). (1988). Technical Change and Economic Theory. Londres: Pinter Publisher.

Forsyth, S. (2005). Hollywood recargado: el cine como una mercancía imperial. Socialist Register 2005: el imperio recargado, 145-164. Buenos Aires: CLACSO.

Hardin, G. (diciembre, 1968). The Tragedy of the Commons. Science, 162(3859), pp. 1243-1248. Recuperado de https://bit.ly/2q8FkZf/

Harvey, D. (2003). El nuevo imperialismo. Madrid: Akal.

Heller, M. (enero, 1998). The Tragedy of the Anticommons. Harvard Law Review, 111(3). Recuperado de https://bit.ly/2naQ3Sj/

Lebert, D. y Vercellone, C. (2006). Il ruolo della conoscenza nella dinamica di lungo periodo del capitalismo. En C. Vercellone (ed.), Capitalismo cognitivo. Conoscenza e finanza nell'epoca postfordista (pp. 19-37). Roma: Manifestolibri.

Lebert, D. y Vercellone, C. (2011). El rol del conocimiento en la dinámica de largo plazo del capitalismo. En C. Vercellone (2011): Capitalismo cognitivo. Renta, saber y valor en la época posfordista (pp.31-55). Buenos Aires: Prometeo.

Lessig, L. (2005). Por una cultura libre. Madrid: Traficantes de Sueños.

López, A. (1996). Las ideas evolucionistas en economía: una visión de conjunto. Buenos Aires: Pensamiento Económico, 1. Recuperado de https://bit. ly/2vqC $52 \mathrm{r} /$

Lundvall, B. A. (1992). National System of Innovation: Towards a Theory of Innovation and Interactive Learning. Londres: Pinter Publisher.

Merino, G. (2018). Los tratados comerciales y la era Trump. Realidad Económica, 313(47), 9-40. Buenos Aires: IADE. Recuperado de https://bit. ly/2KtWDMX/

Míguez, P. (2013). El Estado capitalista, la crisis financiera y el debate ImperioImperialismo. En J. Kan y R. Pascual (eds.) Integrados (?) las relaciones internacionales y la integración regional latinoamericana en debate (pp. 89-119). Buenos Aires: Imago Mundi.

Míguez, P. (2013-2014). Del General Intellect a las tesis del "Capitalismo Cognitivo": aportes para el estudio del capitalismo del siglo XXI. Bajo el 
Volcán, Revista de Sociología de la Benemérita Universidad Autónoma de Puebla, 13(21), 27-57, septiembre 2013/febrero 2014.

Míguez, P. (mayo-septiembre, 2017). Capital global, integración regional y Estados nacionales en el siglo XXI: más allá de las teorías del imperialismo y de las Relaciones internacionales. Revista Estado y Políticas Públicas, 8, 41-57.

Moulier Boutang, Y. (2004). Riqueza, propiedad, libertad y renta en el capitalismo cognitivo. En Y. Moulier Boutang, A. Corsanni, M. Lazzarato et al. (eds.), Capitalismo cognitivo, propiedad intelectual y creación colectiva (pp. 107-128). Madrid: Traficantes de Sueños.

Negri, A. y Hardt, M. (2002). Imperio. Buenos Aires: Paidós.

Negri, A. y Hardt, M. (2011). Commonwealth. Madrid: Akal.

Nelson, R. y Winter, S. (1982). An Evolutionary Theory f Economic Change. Cambridge, MA: Harvard University Press.

Noble, D. (1979). America by design. Nueva York: Alfred Knopf.

OMPI. (2000). Declaración Mundial sobre Propiedad Intelectual. Organización Mundial de la Propiedad Intelectual.

Pazos, R. (2016). El Código Ingenios y su construcción colaborativa. En R. Ramírez (ed.), Universidad urgente para una sociedad emancipada (pp. 541564). Quito: SENESCYT-IESALC.

Perrota, D. y Porcelli, E. (agosto, 2016). Mercosur 25 años: desafíos en su nueva etapa. Márgenes, Revista de Economía Política, 2. Los Polvorines: Universidad Nacional General Sarmiento-UNGS.

Polanyi, K. (1992). La gran transformación: los orígenes políticos y económicos de nuestro tiempo. México: FCE.

Ramírez, R. (2014). La virtud de los comunes: de los paraísos fiscales al paraíso de los conocimientos abiertos. Quito: Abya-Yala.

Rullani, E. (2004). El capitalismo cognitivo ¿Un deja-vú? En Y. Moulier Boutang et al. (eds.), Capitalismo cognitivo, propiedad intelectual y creación colectiva (pp. 99-106). Madrid: Traficantes de Sueños.

Rullani, E. (mayo, 2000). Le capitalisme cognitif: du déjà-vu. Multitudes, 2, 87-94.

Sádaba, I. (2008). Propiedad intelectual: ¿bienes públicos o mercancías privadas? Madrid: Los Libros de la Catarata.

Sassen, S. (2007). Sociología de la globalización. Buenos Aires: Katz.

Sassen, S. (2010). Territorio, autoridad y derechos: de los ensamblajes medievales a los ensamblajes globales. Buenos Aires: Katz.

Schumpeter, J. (1944). Teoría del desenvolvimiento económico. México DF: FCE. 
Schumpeter, J. (2002/1939). Ciclos económicos: análisis teórico, histórico y estadístico del proceso capitalista. Zaragoza: Prensas Universitarias de Zaragoza.

Sraffa, P. (1975). Producción de mercancías por medio de mercancías. Barcelona: Oikos-Tau.

Vercelli, A. (marzo, 2004). La conquista silenciosa del ciberespacio: creative commons y el diseño de entornos digitales en el nuevo arte regulativo de Internet. Buenos Aires. Recuperado de https://bit.ly/2naIGdx/

Vercellone, C. (2004). Las políticas de desarrollo en tiempos del capitalismo cognitivo. En Y. Moulier Boutang et al. (eds.), Capitalismo cognitivo, propiedad intelectual y creación colectiva (pp. 63-74). Madrid: Traficantes de Sueños.

Vercellone, C. (2009). Crisis de la ley del valor y devenir renta de la ganancia. Apuntes sobre la crisis sistémica del capitalismo cognitivo. En A. Fumagalli, S. Lucarelli, C. Marazzi, S. Mezzadra, A. Negri, C. Vercellone (eds.), La gran crisis de la economía global (pp. 63-98). Madrid: Traficantes de Sueños.

Vercellone, C., Giuliani, A., Brancaccio, F. y Vattimo, P. (2017). Il Comune come modo di produzione. Per una critica dell'economia politica dei beni comuni. Verona: Ombre Corte.

Fecha de recepción: 2018/04/15; Fecha de aceptación: 2018/07/24;

Fecha de publicación: 2018/09/01 